\title{
Erratum to: The gas flow diode effect: theoretical and experimental analysis of moderately rarefied gas flows through a microchannel with varying cross section
}

\author{
I. Graur ${ }^{1}$ T. Veltzke ${ }^{2} \cdot$ J. G. Méolans ${ }^{1} \cdot$ M. T. Ho ${ }^{1} \cdot J$. Thöming ${ }^{2}$
}

Published online: 19 April 2015

(C) Springer-Verlag Berlin Heidelberg 2015

\section{Erratum to: Microfluid Nanofluid (2015) 18:391-402 DOI 10.1007/s10404-014-1445-4}

In the original publication of the article, Eq. (13) is incorrect. This is a result of a mistake occurring during the typesetting stage of the article and it does not affect any of the other results or equations in the article. The correct version of the equation is given below:

$Q^{H}=\frac{2}{3}\left(P_{1}^{2}-P_{2}^{2}\right) \frac{H_{2}^{2}}{H_{2}+1}$
Further, a small mistake occurred when calculating the standard deviation of the experimental results provided in Tables 2, 3, 4, 5, 6 and 7. The mean of all values, however, was stated correctly and the mistake does not affect Fig. 4 visibly. The tables with correct standard deviation are given in the following:

The online version of the original article can be found under doi:10.1007/s10404-014-1445-4.

T. Veltzke

tveltzke@uni-bremen.de

I. Graur

irina.martin@univ-amu.fr

J. G. Méolans

joseph.meolans@univ-amu.fr

M. T. Ho

mtho@polytech.univ-mrs.fr

J. Thöming

thoeming@uni-bremen.de

1 CNRS, IUSTI UMR 7343, Aix-Marseille Université, 13453 Marseille, France

2 Center for Environmental Research and Sustainable Technology (UFT), University of Bremen, Leobener Strasse 1, 28359 Bremen, Germany 
Table 2 Experimental results obtained in diffusor direction on the tapered channel according to Fig. 2 with $\mathrm{CO}_{2}$ as working gas, analytical solution, numerical solution

\begin{tabular}{|c|c|c|c|c|c|c|}
\hline \multirow[t]{2}{*}{$p_{1}(\mathrm{kPa})$} & \multirow[t]{2}{*}{$p_{2}(\mathrm{kPa})$} & \multirow[t]{2}{*}{$T_{0}\left({ }^{\circ} \mathrm{C}\right)$} & \multicolumn{3}{|l|}{$\dot{M}\left(10^{-9} \mathrm{~kg} \mathrm{~s}^{-1}\right)$} & \multirow{2}{*}{$\begin{array}{l}\alpha(\%) \\
\text { Num. }\end{array}$} \\
\hline & & & Exp. & Anal. & Num. & \\
\hline $23.0389 \pm 0.0963$ & $3.0266 \pm 0.0949$ & 20.04 & $2.411 \pm 0.047$ & 2.6041 & 2.7810 & 13.3 \\
\hline $28.3679 \pm 0.0852$ & $3.3626 \pm 0.0943$ & 20.03 & $3.404 \pm 0.045$ & 3.5473 & 3.7466 & 9.1 \\
\hline $33.7133 \pm 0.0746$ & $3.7084 \pm 0.0721$ & 20.05 & $4.513 \pm 0.047$ & 4.6146 & 4.8329 & 6.6 \\
\hline $39.0586 \pm 0.0887$ & $4.0720 \pm 0.0768$ & 20.05 & $5.733 \pm 0.049$ & 5.8039 & 6.0353 & 5.0 \\
\hline $44.4236 \pm 0.0821$ & $4.4461 \pm 0.0797$ & 20.05 & $7.067 \pm 0.059$ & 7.1204 & 7.3634 & 4.0 \\
\hline $55.1305 \pm 0.0816$ & $5.1696 \pm 0.0639$ & 20.07 & $10.049 \pm 0.074$ & 10.1177 & 10.3803 & 3.2 \\
\hline $66.1574 \pm 0.0712$ & $5.9504 \pm 0.0662$ & 20.06 & $13.653 \pm 0.080$ & 13.7189 & 13.9981 & 2.5 \\
\hline
\end{tabular}

Measurements were performed in triplicate and arithmetic mean and standard deviation are calculated. The deviation $\alpha$ of the numerical solution to the experimental results is: $\left|\left(\dot{M}_{\text {exp }} / \dot{M}_{\text {num }}\right)-1\right| \cdot 100 \%$

Table 3 Experimental results obtained in nozzle direction on the tapered channel according to Fig. 2 with $\mathrm{CO}_{2}$ as working gas, analytical solution, numerical solution

\begin{tabular}{|c|c|c|c|c|c|c|}
\hline \multirow[t]{2}{*}{$p_{1}(\mathrm{kPa})$} & \multirow[t]{2}{*}{$p_{2}(\mathrm{kPa})$} & \multirow[t]{2}{*}{$T_{0}\left({ }^{\circ} \mathrm{C}\right)$} & \multicolumn{3}{|l|}{$\dot{M}\left(10^{-9} \mathrm{~kg} \mathrm{~s}^{-1}\right)$} & \multirow{2}{*}{$\begin{array}{l}\alpha(\%) \\
\text { Num. }\end{array}$} \\
\hline & & & Exp. & Anal. & Num. & \\
\hline $23.0154 \pm 0.0459$ & $3.0140 \pm 0.0358$ & 20.10 & $2.588 \pm 0.042$ & 3.1587 & 3.2192 & 19.6 \\
\hline $28.3679 \pm 0.0530$ & $3.3753 \pm 0.0374$ & 20.10 & $3.656 \pm 0.052$ & 4.2626 & 4.3396 & 15.8 \\
\hline $33.7229 \pm 0.0596$ & $3.7466 \pm 0.0415$ & 20.10 & $4.847 \pm 0.046$ & 5.4891 & 5.5829 & 13.2 \\
\hline $39.0837 \pm 0.0634$ & $4.1230 \pm 0.0514$ & 20.07 & $6.139 \pm 0.061$ & 6.8407 & 6.9516 & 11.7 \\
\hline $44.4620 \pm 0.0603$ & $4.5079 \pm 0.0442$ & 20.07 & $7.542 \pm 0.053$ & 8.3193 & 8.4468 & 10.7 \\
\hline $55.1912 \pm 0.0522$ & $5.2426 \pm 0.0376$ & 20.08 & $10.662 \pm 0.065$ & 11.6449 & 11.8047 & 9.7 \\
\hline $66.2069 \pm 0.0694$ & $6.0228 \pm 0.0435$ & 20.05 & $14.354 \pm 0.099$ & 15.5730 & 15.7628 & 8.9 \\
\hline
\end{tabular}

Measurements were performed in triplicate and arithmetic mean and standard deviation are calculated. The deviation $\alpha$ of the numerical solution to the experimental results is: $\left|\left(\dot{M}_{\text {exp }} / \dot{M}_{\text {num }}\right)-1\right| \cdot 100 \%$

Table 4 Experimental results obtained in diffusor direction on the tapered channel according to Fig. 2 with $\mathrm{N}_{2}$ as working gas, analytical solution, numerical solution

\begin{tabular}{|c|c|c|c|c|c|c|}
\hline \multirow[t]{2}{*}{$p_{1}(\mathrm{kPa})$} & \multirow[t]{2}{*}{$p_{2}(\mathrm{kPa})$} & \multirow[t]{2}{*}{$T_{0}\left({ }^{\circ} \mathrm{C}\right)$} & \multicolumn{3}{|l|}{$\dot{M}\left(10^{-9} \mathrm{~kg} \mathrm{~s}^{-1}\right)$} & \multirow{2}{*}{$\begin{array}{l}\alpha(\%) \\
\text { Num. }\end{array}$} \\
\hline & & & Exp. & Anal. & Num. & \\
\hline $25.5150 \pm 0.0955$ & $3.3040 \pm 0.0581$ & 20.08 & $1.722 \pm 0.044$ & 2.0490 & 2.2330 & 22.9 \\
\hline $31.4279 \pm 0.0680$ & $3.6811 \pm 0.0295$ & 20.08 & $2.431 \pm 0.040$ & 2.7513 & 2.9595 & 17.9 \\
\hline $37.3339 \pm 0.0457$ & $4.0762 \pm 0.0531$ & 20.05 & $3.223 \pm 0.011$ & 3.5326 & 3.7636 & 14.4 \\
\hline $43.2610 \pm 0.0577$ & $4.4717 \pm 0.0475$ & 20.06 & $4.095 \pm 0.013$ & 4.3972 & 4.6453 & 11.8 \\
\hline $49.1804 \pm 0.0175$ & $4.8795 \pm 0.0108$ & 20.07 & $5.048 \pm 0.034$ & 5.3408 & 5.6053 & 9.9 \\
\hline $61.0077 \pm 0.0474$ & $5.6739 \pm 0.0210$ & 20.06 & $7.178 \pm 0.043$ & 7.4699 & 7.7561 & 7.5 \\
\hline $73.2224 \pm 0.0176$ & $6.5315 \pm 0.0254$ & 20.06 & $9.751 \pm 0.023$ & 10.0061 & 10.3127 & 5.4 \\
\hline
\end{tabular}

Measurements were performed in triplicate and arithmetic mean and standard deviation are calculated. The deviation $\alpha$ of the numerical solution to the experimental results is: $\left|\left(\dot{M}_{\text {exp }} / \dot{M}_{\text {num }}\right)-1\right| \cdot 100 \%$ 
Table 5 Experimental results obtained in nozzle direction on the tapered channel according to Fig. 2 with $\mathrm{N}_{2}$ as working gas, analytical solution, numerical solution

\begin{tabular}{|c|c|c|c|c|c|c|}
\hline \multirow[t]{2}{*}{$p_{1}(\mathrm{kPa})$} & \multirow[t]{2}{*}{$p_{2}(\mathrm{kPa})$} & \multirow[t]{2}{*}{$T_{0}\left({ }^{\circ} \mathrm{C}\right)$} & \multicolumn{3}{|l|}{$\dot{M}\left(10^{-9} \mathrm{~kg} \mathrm{~s}^{-1}\right)$} & \multirow{2}{*}{$\begin{array}{l}\alpha(\%) \\
\text { Num. }\end{array}$} \\
\hline & & & Exp. & Anal. & Num. & \\
\hline $25.4982 \pm 0.0234$ & $3.3167 \pm 0.0131$ & 20.08 & $1.848 \pm 0.027$ & 2.5415 & 2.5966 & 28.8 \\
\hline $31.4365 \pm 0.0376$ & $3.7172 \pm 0.0181$ & 20.12 & $2.611 \pm 0.019$ & 3.3859 & 3.4543 & 24.4 \\
\hline $37.0293 \pm 0.0284$ & $4.0850 \pm 0.0142$ & 20.10 & $3.462 \pm 0.019$ & 4.2574 & 4.3394 & 20.2 \\
\hline $42.9162 \pm 0.0304$ & $4.4908 \pm 0.0212$ & 20.26 & $4.384 \pm 0.034$ & 5.2477 & 5.3447 & 18.0 \\
\hline $48.8057 \pm 0.0230$ & $4.9114 \pm 0.0696$ & 20.26 & $5.387 \pm 0.012$ & 6.3192 & 6.4314 & 16.2 \\
\hline $60.6650 \pm 0.0216$ & $5.7264 \pm 0.0327$ & 20.31 & $7.615 \pm 0.023$ & 8.7218 & 8.8644 & 14.1 \\
\hline $72.7721 \pm 0.0331$ & $6.5730 \pm 0.0234$ & 20.09 & $10.252 \pm 0.020$ & 11.5187 & 11.6916 & 12.3 \\
\hline
\end{tabular}

Measurements were performed in triplicate and arithmetic mean and standard deviation are calculated. The deviation $\alpha$ of the numerical solution to the experimental results is: $\left|\left(\dot{M}_{\text {exp }} / \dot{M}_{\text {num }}\right)-1\right| \cdot 100 \%$

Table 6 Experimental results obtained in diffusor direction on the tapered channel according to Fig. 2 with Ar (argon) as working gas, analytical solution, numerical solution

\begin{tabular}{|c|c|c|c|c|c|c|}
\hline \multirow[t]{2}{*}{$\overline{p_{1}(\mathrm{kPa})}$} & \multirow[t]{2}{*}{$p_{2}(\mathrm{kPa})$} & \multirow[t]{2}{*}{$T_{0}\left({ }^{\circ} \mathrm{C}\right)$} & \multicolumn{3}{|l|}{$\dot{M}\left(10^{-9} \mathrm{~kg} \mathrm{~s}^{-1}\right)$} & \multirow{2}{*}{$\begin{array}{l}\alpha(\%) \\
\text { Num. }\end{array}$} \\
\hline & & & Exp. & Anal. & Num. & \\
\hline $24.1557 \pm 0.0517$ & $3.1894 \pm 0.0273$ & 20.29 & $1.855 \pm 0.035$ & 2.2111 & 2.4305 & 23.7 \\
\hline $29.8508 \pm 0.0545$ & $3.5046 \pm 0.0275$ & 20.30 & $2.619 \pm 0.053$ & 2.9675 & 3.2207 & 18.7 \\
\hline $35.0942 \pm 0.0649$ & $3.8842 \pm 0.0242$ & 20.30 & $3.494 \pm 0.049$ & 3.7328 & 4.0099 & 12.9 \\
\hline $40.4200 \pm 0.0402$ & $4.2844 \pm 0.0281$ & 20.29 & $4.440 \pm 0.039$ & 4.5815 & 4.8817 & 9.0 \\
\hline $46.0627 \pm 0.0674$ & $4.6966 \pm 0.0457$ & 20.30 & $5.459 \pm 0.057$ & 5.5599 & 5.8788 & 7.1 \\
\hline $57.1809 \pm 0.0531$ & $5.4635 \pm 0.0570$ & 20.30 & $7.762 \pm 0.072$ & 7.7283 & 8.0797 & 3.9 \\
\hline $68.6523 \pm 0.0605$ & $6.2922 \pm 0.0259$ & 20.48 & $10.537 \pm 0.073$ & 10.2871 & 10.6610 & 1.2 \\
\hline
\end{tabular}

Measurements were performed in triplicate and arithmetic mean and standard deviation are calculated. The deviation $\alpha$ of the numerical solution to the experimental results is: $\left|\left(\dot{M}_{\text {exp }} / \dot{M}_{\text {num }}\right)-1\right| \cdot 100 \%$

Table 7 Experimental results obtained in nozzle direction on the tapered channel according to Fig. 2 with Ar (argon) as working gas, analytical solution, numerical solution

\begin{tabular}{|c|c|c|c|c|c|c|}
\hline \multirow[t]{2}{*}{$p_{1}(\mathrm{kPa})$} & \multirow[t]{2}{*}{$p_{2}(\mathrm{kPa})$} & \multirow[t]{2}{*}{$T_{0}\left({ }^{\circ} \mathrm{C}\right)$} & \multicolumn{3}{|l|}{$\dot{M}\left(10^{-9} \mathrm{~kg} \mathrm{~s}^{-1}\right)$} & \multirow{2}{*}{$\begin{array}{l}\alpha(\%) \\
\text { Num. }\end{array}$} \\
\hline & & & Exp. & Anal. & Num. & \\
\hline $23.9157 \pm 0.0294$ & $3.2167 \pm 0.0346$ & 20.08 & $1.998 \pm 0.023$ & 2.7266 & 2.7895 & 28.4 \\
\hline $29.4861 \pm 0.0311$ & $3.5476 \pm 0.0420$ & 20.06 & $2.822 \pm 0.023$ & 3.6227 & 3.6999 & 23.7 \\
\hline $34.8385 \pm 0.0409$ & $3.9118 \pm 0.0374$ & 20.04 & $3.759 \pm 0.032$ & 4.5532 & 4.6453 & 19.1 \\
\hline $40.3653 \pm 0.0440$ & $4.2902 \pm 0.0286$ & 20.06 & $4.762 \pm 0.048$ & 5.5904 & 5.6985 & 16.4 \\
\hline $46.0374 \pm 0.0501$ & $4.6987 \pm 0.0596$ & 20.31 & $5.832 \pm 0.043$ & 6.7281 & 6.8533 & 14.9 \\
\hline $57.1578 \pm 0.0368$ & $5.4656 \pm 0.0331$ & 20.33 & $8.245 \pm 0.045$ & 9.2108 & 9.3707 & 12.0 \\
\hline $68.6183 \pm 0.0449$ & $6.2951 \pm 0.0431$ & 20.33 & $11.092 \pm 0.056$ & 12.0960 & 12.2903 & 9.8 \\
\hline
\end{tabular}

Measurements were performed in triplicate and arithmetic mean and standard deviation are calculated. The deviation $\alpha$ of the numerical solution to the experimental results is: $\left|\left(\dot{M}_{\exp } / \dot{M}_{\text {num }}\right)-1\right| \cdot 100 \%$ 
Furthermore, a mistake occurred when calculating $\bar{K} n$ according to Eq. (11) with $\bar{p}=0.25\left(p_{1}^{\text {noz }}+p_{2}^{\text {noz }}+\right.$ $\left.p_{1}^{\mathrm{dif}}+p_{2}^{\mathrm{dif}}\right)$. The corrected values are given in Tables 8,9 and 10 below:

Table 8 Mean Knudsen number and experimental and numerically calculated diodicity of carbon dioxide $\left(\mathrm{CO}_{2}\right)$ at $20.07{ }^{\circ} \mathrm{C}$

\begin{tabular}{llll}
\hline $\bar{K} n$ & $D$ & & $\alpha(\%)$ \\
\cline { 2 - 3 } & Exp. & Num. & Num. \\
\hline $0.2382 \pm 0.0447$ & $1.0755 \pm 0.0284$ & 1.1598 & 7.27 \\
$0.1955 \pm 0.0367$ & $1.0742 \pm 0.0218$ & 1.1584 & 7.27 \\
$0.1657 \pm 0.0311$ & $1.0737 \pm 0.0157$ & 1.1548 & 7.02 \\
$0.1437 \pm 0.0270$ & $1.0696 \pm 0.0148$ & 1.1506 & 7.04 \\
$0.1268 \pm 0.0238$ & $1.0657 \pm 0.0123$ & 1.1455 & 6.96 \\
$0.1028 \pm 0.0193$ & $1.0588 \pm 0.0105$ & 1.1350 & 6.71 \\
$0.0860 \pm 0.0161$ & $1.0500 \pm 0.0098$ & 1.1246 & 6.63 \\
\hline
\end{tabular}

$\bar{K} n$ and $D$ are calculated according to Eqs. (11), (23), (30) and (31) using values stated in Tables 1,2 and 3. The deviation $\alpha$ of the numerical solution to the experimental results is: $\left|\left(D_{\exp } / D_{\text {num }}\right)-1\right| \cdot 100 \%$

Table 9 Mean Knudsen number and experimental and numerically calculated diodicity of nitrogen $\left(\mathrm{N}_{2}\right)$ at $20.12{ }^{\circ} \mathrm{C}$

\begin{tabular}{llll}
\hline $\bar{K} n$ & $D$ & & $\alpha(\%)$ \\
\cline { 2 - 3 } & Exp. & Num. & Num. \\
\hline $0.3849 \pm 0.0722$ & $1.0745 \pm 0.0319$ & 1.1646 & 7.74 \\
$0.3157 \pm 0.0592$ & $1.0743 \pm 0.0194$ & 1.1669 & 7.93 \\
$0.2688 \pm 0.0504$ & $1.0920 \pm 0.0073$ & 1.1723 & 6.85 \\
$0.2332 \pm 0.0437$ & $1.0880 \pm 0.0094$ & 1.1694 & 6.96 \\
$0.2059 \pm 0.0386$ & $1.0838 \pm 0.0078$ & 1.1654 & 7.00 \\
$0.1668 \pm 0.0313$ & $1.0732 \pm 0.0072$ & 1.1562 & 7.18 \\
$0.1394 \pm 0.0261$ & $1.0646 \pm 0.0034$ & 1.1480 & 7.27 \\
\hline
\end{tabular}

$\bar{K} n$ and $D$ are calculated according to Eqs. (11), (23), (30) and (31) using values stated in Tables 1,4 and 5. The deviation $\alpha$ of the numerical solution to the experimental results is: $\left|\left(D_{\exp } / D_{\text {num }}\right)-1\right| \cdot 100 \%$

Table 10 Mean Knudsen number and experimental and numerically calculated diodicity of argon (Ar) at $20.25^{\circ} \mathrm{C}$

\begin{tabular}{llll}
\hline $\bar{K} n$ & $D$ & $\alpha(\%)$ \\
\cline { 2 - 3 } & Exp. & Num. & \\
\hline $0.4097 \pm 0.0768$ & $1.0993 \pm 0.0241$ & 1.1716 & 6.17 \\
$0.3362 \pm 0.0630$ & $1.1053 \pm 0.0241$ & 1.1782 & 6.19 \\
$0.2871 \pm 0.0538$ & $1.0921 \pm 0.0181$ & 1.1759 & 7.13 \\
$0.2498 \pm 0.0468$ & $1.0755 \pm 0.0145$ & 1.1706 & 8.12 \\
$0.2200 \pm 0.0413$ & $1.0697 \pm 0.0140$ & 1.1671 & 8.34 \\
$0.1783 \pm 0.0334$ & $1.0630 \pm 0.0115$ & 1.1607 & 8.42 \\
$0.1491 \pm 0.0280$ & $1.0538 \pm 0.0091$ & 1.1540 & 8.68 \\
\hline
\end{tabular}

$\bar{K} n$ and $D$ are calculated according to Eqs. (11), (23), (30) and (31) using values stated in Tables 1, 6 and 7. The deviation $\alpha$ of the numerical solution to the experimental results is: $\left(D_{\exp } / D_{\text {num }}\right)-1 \mid \cdot 100 \%$
Accordingly, Fig. 5 appears slightly different.

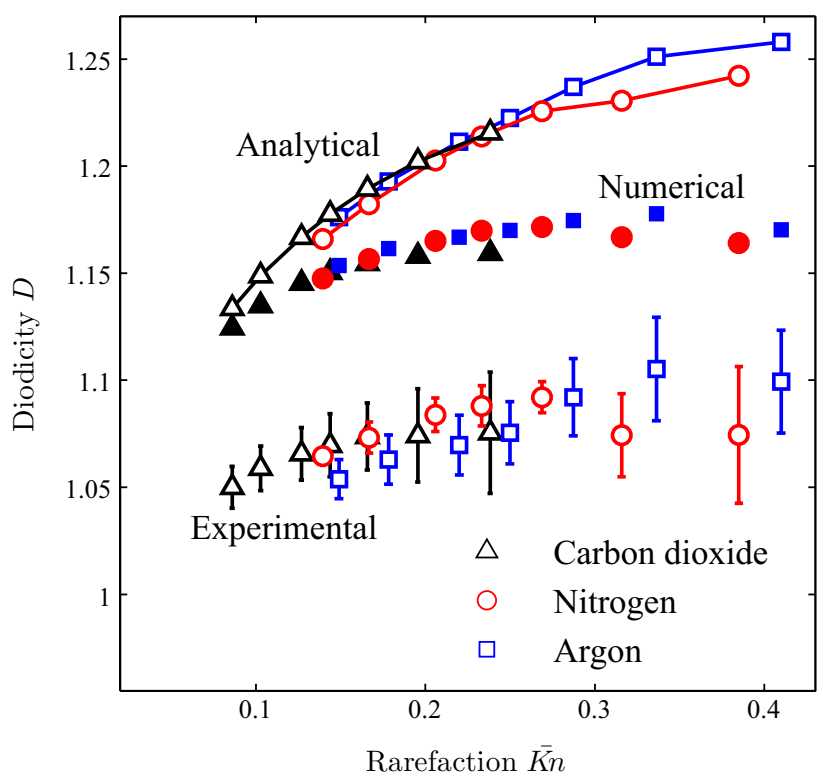

Fig. 5 Diodicity versus mean Knudsen number. Analytical data (interconnected with lines), numerical data (filled symbols) and experimental data (open symbols) are prepared according to Eqs. (11) and (23) with values stated in Tables 2, 3, 4, 5, 6 and 7 in "Appendix". The experimental uncertainty of $D$ is expressed by vertical errorbars that are calculated according to Eq. (30). The horizontal errorbars are not shown but the experimental uncertainty of $\bar{K} n$ according to Eq (31) is tabulated. All depicted values are provided in Tables 8, 9 and 10 in the "Appendix"

Acknowledgments We would like to acknowledge Vadiraj Hemadri who called attention to this mistake. We apologize for any inconvenience. 